\title{
THE EFFECT OF PREOPERATIVE TRANEXAMIC ACID ON BLOOD LOSS AFTER CARDIAC OPERATIONS IN CHILDREN
}

\section{Ze'ev Zonis, MD ${ }^{\mathrm{a}}$}

Michael Seear, FRCPC

Clayton Reichert, $\mathrm{MD}^{\mathrm{b}}$

Suvro Sett, FRCSC

Clair Allen, BSc(Pharm) ${ }^{\mathrm{d}}$

\begin{abstract}
Children undergoing cardiac operations in which cardiopulmonary bypass is used are at risk of significant postoperative blood loss. The acquired coagulopathy is complex but is thought to be due, in part, to excessive fibrinolysis. We examined the possibility of reducing postoperative blood loss in children by using the antifibrinolytic drug tranexamic acid. Using a prospective, randomized, double-blind study design, we administered a single dose of tranexamic acid $(50 \mathrm{mg} / \mathrm{kg}$ intravenously) or saline placebo, before skin incision, in 88 children undergoing cardiac operations. Postoperative blood loss and fluid replacement were recorded for the next 24 hours. In addition, hemoglobin, platelet counts, and coagulation measures were recorded every 6 hours. When all patients were examined, there was no significant difference in postoperative blood loss between the treated and placebo groups $(21.2 \pm 12 \mathrm{ml} / \mathrm{kg}$ per 24 hours, tranexamic acid, vs $27.2 \pm$ $20.3 \mathrm{mls} / \mathrm{kg}$ per 24 hours, placebo). However, when the children with cyanosis were analyzed separately, there was a highly significant difference in blood loss between the groups during the first 6 hours $(11.2 \pm 3.7 \mathrm{ml} / \mathrm{kg}$ per 6 hours, tranexamic acid, vs $27.2 \pm 11.4 \mathrm{mls} / \mathrm{kg}$ per 6 hours, placebo; $p<0.002)$, as well as the overall 24 hour study period $(23.7 \pm 7.5 \mathrm{mls} / \mathrm{kg}$ per 24 hours, tranexamic acid, vs $48.9 \pm 27.6 \mathrm{mls} / \mathrm{kg}$ per 24 hours, placebo; $p<0.02$ ). Also significantly less blood and blood products were administered to the treated cyanosed group. Tranexamic acid produced a significant reduction in postoperative blood loss and blood product requirements in children with cyanosis undergoing heart operations. The drug had no effect in children without cyanosis or those requiring a second thoracotomy. (J Thorac Cardiovasc Surg 1996;111:982-7)
\end{abstract}

$\mathrm{C}$ hildren undergoing cardiac bypass operations are at risk of significant postoperative bleeding. ${ }^{1,2} \mathrm{Ac}$ cording to one of our own studies, ${ }^{3}$ the average child loses $30 \mathrm{ml} / \mathrm{kg}$, roughly half the child's blood volume, in the first 24 hours after a routine cardiac operation. Many lose significantly more than this. It is commonly claimed that children with cyanosis and those under-

From the Departments of Intensive Care, ${ }^{a}$ Anesthesia, ${ }^{b}$ Surgery, ${ }^{c}$

- and Pharmacology, ${ }^{\mathrm{d}}$ British Columbia's Children's Hospital, Vancouver, British Columbia, Canada.

This work was supported in part by a grant from Kabi Pharmacia, Mississauga, Ontario, Canada. Dr. Zonis is partially supported by a grant from the American Physician's Fellowship.

Received for publication Feb. 17, 1995; accepted for publication July 26, 1995.

Address for reprints: Michael Seear, FRCPC, British Columbia's Children's Hospital, Intensive Care Unit, 4480 Oak St., Vancouver, British Columbia, Canada V6H 3 V4.

Copyright (C) 1996 by Mosby-Year Book, Inc.

$0022-5223 / 96 \$ 5.00+0 \quad \mathbf{1 2 / 1 / 6 8 1 9 8}$ going a second thoracotomy are at particular risk of excessive blood loss. ${ }^{4}$ Apart from the cost associated with large transfusions, the patient is also exposed to the dangers of blood transfusion ${ }^{5}$ and, in some cases, reoperation. ${ }^{2}$ The most common finding at the second thoracotomy is a generalized ooze of blood from the surgical field, suggesting an acquired coagulopathy induced by cardiac bypass.

Many abnormalities of coagulation have been described after cardiac surgery, ${ }^{1,6}$ including thrombocytopenia, thrombocytopathy, decreased clotting factors, increased fibrinolysis, inadequate heparin neutralization, and disseminated intravascular coagulation. Despite the difficulty of determining which abnormality is most significant, the consensus is that the main cause of nonoperative blood loss after cardiopulmonary bypass is a combination of excessive fibrinolysis ${ }^{7}$ and an acquired platelet defect. ${ }^{1}$ Consequently, attempts have been made to reduce blood loss with the use of antifibrinolytic drugs. 8,9 
Fibrinolysis follows reversible binding between lysine residues in fibrin and specific receptor sites in plasminogen. Reversible inhibition of absorption by lysine analogs, such as epsilon aminocaproic acid or tranexamic acid, displaces plasminogen and effectively inhibits fibrinolysis. ${ }^{10}$ Earlier studies used epsilon aminocaproic acid, but a newer drug, tranexamic acid, is roughly ten times more potent, has a longer half-life, and is now more commonly used. Both drugs have few side effects. ${ }^{11}$ The naturally occurring inhibitor of proteolysis, aprotinin, is used less often than lysine analogs because of its high cost. Plasmin also binds to platelets and activates them. Inhibiting this step with lysine analogs has been shown to preserve platelet adenosine diphosphate levels, ${ }^{12}$ as well as to decrease blood loss. ${ }^{13}$

Both epsilon aminocaproic acid ${ }^{14,15}$ and tranexamic acid ${ }^{13,16}$ have been shown to reduce blood loss in adults, although not in all studies. ${ }^{17}$ Only one pediatric study has shown a slight benefit that was more pronounced in cyanotic children. ${ }^{18}$ We investigated the possible benefit of antifibrinolytic therapy in children by use of a double-blind, randomized, prospective study of tranexamic acid versus saline placebo in 88 patients undergoing cardiac bypass operations.

The primary objective of this study was to investigate whether a single preoperative dose of tranexamic acid affects the amount of blood loss after cardiopulmonary bypass in children undergoing cardiac operations. The secondary study objective was to investigate that effect in two high-risk subgroups: children with cyanotic heart disease, and those with a history of previous thoracotomy.

\section{Methods}

The study was conducted in the Intensive Care Unit at the British Columbia's Children's Hospital. All operations were performed by the same two cardiac surgeons. Postoperative management was provided by three pediatric intensivists. Ethical approval was obtained from the Clinical Screening Committee of the University of British Columbia. Eighty-eight consecutive patients requiring cardiac operations were enrolled. All legal guardians were aware of the study and gave informed consent. Preenrollment exclusion criteria consisted of a history of hematuria, renal failure, previous thrombotic episodes, or past bleeding complications.

Study design. Using a system of sealed envelopes, we allocated the patients to one of two groups: the treatment group received a single $50 \mathrm{mg} / \mathrm{kg}$ intravenous dose of tranexamic acid (Cyclokapron, Kabi Pharmacia, Mississauga, Ontario, Canada) and a control group received an equivalent volume of saline placebo. Drugs were administered by the anesthetist before the first skin incision.
Only the pharmacist was aware of the patient treatment groups.

Because no literature exists concerning the use of tranexamic acid in pediatric heart surgery, the dose range had to be extrapolated from adult work. Unfortunately, literature recommendations range from $7 \mathrm{mg} / \mathrm{kg}^{12}$ to 100 to $120 \mathrm{mg} / \mathrm{kg} .{ }^{19}$ It is generally claimed that 10 to $15 \mathrm{mg} / \mathrm{kg}$ of tranexamic acid inhibits fibrinolysis in normal subjects. ${ }^{8,10}$ In discussion with the surgical service in Toronto General Hospital, who have extensive experience with the drug, ${ }^{19}$ we decided on a single preoperative dose of 50 $\mathrm{mg} / \mathrm{kg}$ given by slow intravenous infusion. Because the drug was given before the first skin incision, we did not alter the dose to account for subsequent differences in bypass priming volume.

Because estimates of intraoperative blood loss are too inaccurate for study purposes, we collected and measured total chest tube drainage in 6,12 , and 24 hour blocks, starting from the time of chest closure. No correction was made for the hematocrit value of chest tube blood. In addition, the total amount of blood products transfused, hemostatic parameters (prothrombin time, partial thromboplastin time, platelets, and fibrinogen), hemoglobin, and urine output were also recorded every 6 hours.

Five percent albumin was used to replace all chest tube losses. The indication to administer blood or other blood products was at the discretion of the attending intensivists who where blinded to the group assignment of the patients.

Sample size calculation. Using blood loss over the first postoperative 24 hours as our primary outcome, we expected the mean blood loss to be $25 \mathrm{ml} / \mathrm{kg}$ per 24 hours with a standard deviation of $75 \%$. We wanted to be able to detect a difference of at least $50 \%$ in the treatment group.

Choosing an $\alpha$ of 0.05 , and a $\beta$ of 0.2 (power of $80 \%$ ), the sample size calculation yields 36 patients in each group. To compensate for patient exclusions, we arbitrarily increased this number by $20 \%$ to give 44 children in each group.

Statistical analysis. All values are expressed as mean \pm standard deviation. Discrete differences between the two groups were compared by unpaired $t$ test except for within-group comparisons of preoperative and postoperative coagulation data, when a paired $t$ test was used. Frequency data were compared by means of Fisher's exact test. Serial measurements, such as blood loss with time, were compared by means of repeated measures analysis of variance, followed by Duncan's multiple range post hoc test for significant values of $F$. In keeping with many pilot studies, it was necessary to make multiple statistical comparisons. To compensate for the increased chance of a type I error, the commonly accepted level of significance was halved to $2.5 \%$.

\section{Results}

Patient exclusions. No patients met the preenrollment exclusion criteria. Of the 88 patients enrolled, six were excluded during the study period. Three of these, all from the placebo group, were returned to the operating room for mediastinal 
Table I. Patient characteristics

\begin{tabular}{lcc}
\hline & Tranexamic acid & Placebo \\
\hline No. of patients & 40 & 42 \\
Age (mo) & $62.8 \pm 58.1$ & $52.6 \pm 51.2$ \\
Age range & 1 day-14 years & 6 days-13 years \\
Weight (kg) & $21.3 \pm 16.9$ & $16.4 \pm 12.5$ \\
Bypass time (min) & $80.5 \pm 42.1$ & $73.6 \pm 31.6$ \\
Crossclamp time (min) & $48.9 \pm 29.3(n=37)$ & $47.6 \pm 26.5(n=42)$ \\
Circulatory arrest time (min) & $20.7 \pm 16.6(n=13)$ & $15.7 \pm 10.6(n=17)$ \\
Male/female & $19 / 21$ & $21 / 21$ \\
Down syndrome & 2 & 5 \\
Previous thoracotomy & 14 & 10 \\
Cyanotic heart disease & 8 & 10 \\
Type of repair & & 10 \\
ASD repair (primum and secundum) & 16 & 7 \\
VSD repair & 9 & 5 \\
Tetralogy of Fallot repair & 1 & 3 \\
Bidirectional Glenn shunt & 0 & 2 \\
Fontan operation & 4 & 1 \\
Arterial switch operation & 1 & 2 \\
Pulmonary artery conduit & 3 & 5 \\
Aortic valvotomy & 2 & 2 \\
Mitral valve replacement & 0 & 5 \\
Others & 4 & \\
\hline
\end{tabular}

$\overline{A S D}$, Atrial septal defect; $V S D$, ventricular septal defect.

Table II. Preoperative and immediate postoperative coagulation results for the two treatment groups

\begin{tabular}{|c|c|c|c|c|}
\hline & \multicolumn{2}{|c|}{ Tranexamic acid $(n=40)$} & \multicolumn{2}{|c|}{ Placebo $(n=42)$} \\
\hline & Preoperative & Postoperative & Preoperative & Postoperative \\
\hline Hemoglobin $(\mathrm{gm} / \mathrm{L})$ & $130.5 \pm 21.4$ & $112.8 \pm 20.8$ & $132.0 \pm 21.9$ & $114.5 \pm 21.7$ \\
\hline Hematocrit & $0.376 \pm 0.058$ & $0.326 \pm 0.056$ & $0.380 \pm 0.061$ & $0.329 \pm 0.060$ \\
\hline Prothrombin time (sec) & $12.5 \pm 1.0$ & $14.9 \pm 1.3$ & $12.3 \pm 0.6$ & $14.9 \pm 1.1$ \\
\hline Partial thromboplastin time (sec) & $31.3 \pm 2.9$ & $36.2 \pm 10.3$ & $31.4 \pm 4.1$ & $37.8 \pm 8.5$ \\
\hline Platelet count $\left(\times 10^{9} / \mathrm{L}\right)$ & $312.8 \pm 99.7$ & $160.5 \pm 59.1$ & $328.2 \pm 91.5$ & $159.1 \pm 68.5$ \\
\hline
\end{tabular}

All within-group preoperative and postoperative differences are significant $\overline{(p<0.05)}$. None of the between-group comparisons achieved significance.

exploration during the first 24 hours because of excessive bleeding. A surgical cause for the blood loss was found in each case. In two other cases, also from the placebo group, the study code was broken at the request of the treating intensivist because of excessive blood loss. Both patients were given intravenous tranexamic acid and large infusions of blood products. Neither patient required reoperation. A sixth patient, from the tranexamic acid group, had hypotension on arrival in the intensive care unit. After the patient had been given large volumes of blood products, the surgical site was reexplored. No active bleeding was found. The child had an overt disseminated coagulopathy but subsequently made a good recovery. The reexploration rate in our study was $4.6 \%$, similar to the proportion reported in the literature. ${ }^{2}$ No patients died and no side effects were attributed to the treatment group.
Patient characteristics. The characteristics in the remaining 82 patients are shown in Table I. Apart from minor differences in the type of procedure, the groups are comparable with respect to age, weight, gender, and duration of bypass, crossclamp, and circulatory arrest times. Frequencies of cyanotic lesions, Down syndrome, and repeated thoracotomies were also comparable.

Postoperative blood loss. Preoperative and immediate postoperative (measured immediately after chest closure) coagulation results for the two groups are displayed in Table II. The postbypass coagulopathy in this study was typical of our earlier experience. ${ }^{3}$ Significant within-group reductions were observed in hemoglobin value and platelet count, accompanied by significant increases in prothrombin time and activated partial thromboplastin time. However, no significant differences were seen when 
Table III. Postoperative blood loss

\begin{tabular}{lccc}
\hline \multicolumn{1}{c}{ Variable } & Tranexamic Acid & Placebo & $p$ Value \\
\hline No. of patients & 40 & 42 & \\
$0-6 \mathrm{hr}$ & $9.3 \pm 6.7$ & $13.7 \pm 10.8$ & 0.03 \\
$6-12 \mathrm{hr}$ & $4.2 \pm 2.8$ & $5.0 \pm 4.6$ & NS \\
$12-24 \mathrm{hr}$ & $7.7 \pm 5.1$ & $8.4 \pm 7.6$ & NS \\
Overall $24 \mathrm{hr}$ & $21.2 \pm 12.0$ & $27.2 \pm 20.3$ & NS \\
\hline
\end{tabular}

All blood loss volumes are measured in milliliters per kilogram. NS, Not significant.

Table IV. Postoperative blood loss in the cyanotic subgroup

\begin{tabular}{lccc}
\hline \multicolumn{1}{c}{ Variable } & Tranexamic acid & Placebo & $\overline{p \text { Value }}$ \\
\hline No. of patients & 8 & 10 & \\
$0-6 \mathrm{hr}$ & $11.2 \pm 3.7$ & $27.2 \pm 11.4$ & 0.002 \\
6-12 hr & $5.5 \pm 2.6$ & $7.6 \pm 6.3$ & NS \\
12-24 hr & $7.1 \pm 3.6$ & $14.1 \pm 11.2$ & NS \\
Overall $24 \mathrm{hr}$ & $23.7 \pm 7.5$ & $48.9 \pm 27.6$ & 0.02
\end{tabular}

All blood loss volumes are measured in milliliters per kilogram. NS, Not significant.

the treatment and placebo groups were compared, including postoperative fibrinogen levels $(1.43 \pm$ $0.31 \mathrm{gm} / \mathrm{L}$ placebo, versus $1.60 \pm 0.32 \mathrm{gm} / \mathrm{L}$, tranexamic acid; $p=$ not significant). Postoperative blood losses in the two treatment groups are shown in Table III. No significant difference in total blood loss was seen between the treated and placebo groups when all children were analyzed together.

Second thoracotomy and cyanotic subgroups. The number of patients within the study was sufficient to examine the effect of tranexamic acid in two high-risk subgroups: children with cyanotic heart disease and those with a history of a previous thoracotomy. Table IV shows that blood loss in the subgroup with cyanosis was almost halved after treatment with tranexamic acid $(23.7 \pm 7.5$ vs $46.9 \pm$ $27.6 \mathrm{ml} / \mathrm{kg}$ per 24 hours; $p<0.02$ ). Table $\mathrm{V}$ shows that tranexamic acid appears to have no effect at all in the acyanotic subgroup, either in total blood loss or in any of the measured time blocks $(20.6 \pm 12.8$ $\mathrm{mls} / \mathrm{kg}$ per 24 hours, tranexamic acid, vs $20.4 \pm 12.7$ $\mathrm{mls} / \mathrm{kg}$ per 24 hours, placebo). Apart from a significant difference in hemoglobin levels between children with and without cyanosis $(153.3 \pm 26.9 \mathrm{gm} / \mathrm{L}$, cyanosis, vs $125.1 \pm 14.6 \mathrm{gm} / \mathrm{L}$, without cyanosis; $p=0.01$ ), there were no other differences in preoperative blood work, including prothrombin time, partial thromboplastin time, platelet count, or fibrinogen level. In addition to reducing blood loss in the children with cyanosis, significantly fewer patients with cyanosis required packed red cell trans-
Table V. Postoperative blood loss in the acyanotic subgroup

\begin{tabular}{lccc}
\hline \multicolumn{1}{c}{ Variable } & Tranexamic acid & Placebo & $p$ Value \\
\hline No. of patients & 32 & 32 & \\
$0-6 \mathrm{hr}$ & $8.9 \pm 7.2$ & $9.5 \pm 6.2$ & NS \\
$6-12 \mathrm{hr}$ & $3.9 \pm 2.8$ & $4.3 \pm 3.6$ & NS \\
$12-24 \mathrm{hr}$ & $7.8 \pm 5.3$ & $6.6 \pm 4.9$ & NS \\
Overall $24 \mathrm{hr}$ & $20.6 \pm 12.8$ & $20.4 \pm 12.7$ & NS \\
\hline
\end{tabular}

All blood loss volumes are measured in milliliters per kilogram. NS, Not significant.

Table VI. Twenty-four-hour postoperative blood loss in second thoracotomy and first thoracotomy subgroups

\begin{tabular}{|c|c|c|c|c|c|}
\hline & \multicolumn{2}{|c|}{$\begin{array}{l}\text { Tranexamic } \\
\quad \text { acid }\end{array}$} & \multicolumn{3}{|c|}{ Placebo } \\
\hline & No. & $\begin{array}{c}\text { Blood } \\
\text { loss }\end{array}$ & $\mathrm{No}$ & $\begin{array}{c}\text { Blood } \\
\text { loss }\end{array}$ & $\begin{array}{c}p \\
\text { Value }\end{array}$ \\
\hline Previous thoracotomy & 14 & $20.9 \pm 9.2$ & 10 & $28.7 \pm 24.3$ & NS \\
\hline First thoracotomy & 26 & $21.4 \pm 13.3$ & 32 & $26.8 \pm 18.9$ & NS \\
\hline $\begin{array}{l}\text { Previous thoracotomy } \\
\text { and cyanosis }\end{array}$ & 4 & $28.4 \pm 3.8$ & 5 & $44.2 \pm 25.9$ & NS \\
\hline
\end{tabular}

All blood losses are measured in milliliters per kilogram per 24 hours. NS, Not significant.

fusions $(1 / 8$, tranexamic acid, vs $7 / 10$, placebo; $p=$ $0.02)$ and platelet transfusions $(0 / 8$, tranexamic acid, vs $6 / 10$, placebo; $p=0.01$ ).

The situation was similar in the second thoracotomy subgroup. A nonsignificant trend for greater blood loss in the placebo-treated, second thoracotomy group is shown in Table VI. The same table shows that this difference is largely explained by the reduced blood loss in children with second thoracotomies who had cyanosis. Patient numbers were too small to achieve significance.

\section{Discussion}

Preoperative administration of tranexamic acid to a representative group of children undergoing cardiac operations did not produce a significant reduction in blood loss except during the first 6-hour time block. This difference was entirely due to the drug's effect on children with cyanosis, in whom tranexamic acid roughly halved postoperative blood loss and significantly reduced blood product requirements. The drug had no effect in acyanotic children or those requiring a second thoracotomy. In common with DeLeon and associates, ${ }^{4}$ we found cyanosis, but not second thoracotomy, to be a risk factor for excessive blood loss.

When blood loss is a measured end point, the 
exclusion of patients because of excessive blood losses runs the risk of experimental bias. We also analyzed the results with those who bled heavily included and found that this did not alter the study's final conclusions. Of the six patients excluded for heavy bleeding, five were from the placebo group and four had cyanosis. Inclusion of these patients in the analysis simply strengthened the difference in blood loss between the subgroups with cyanosis. Because there was still no significant drug effect in the patients without cyanosis, the study's conclusions were unchanged.

Several articles have reported reduced postoperative blood loss after the use of preoperative tranexamic acid in adult patients. ${ }^{8,9}$ Direct comparison with adult work is difficult because the study populations differ widely: the mean age is much higher, the majority of patients have coronary artery disease, and very few have cyanotic lesions or Down syndrome. In addition, there is no uniformity in drug dosage or administration. Some studies use continuous infusions of antifibrinolytic drugs ${ }^{16}$ and others give a single drug dose, usually before bypass ${ }^{20}$ but occasionally after bypass. ${ }^{17}$ Even the size of the single dose varies by an order of magnitude from 7 $\mathrm{mg} / \mathrm{kg}^{12}$ up to more than $100 \mathrm{mg} / \mathrm{kg}^{19}$

There is no other report on the use of tranexamic acid in pediatric heart surgery, but some comparison can be made with McClure and Izsak, ${ }^{18}$ who reported a significant reduction in blood loss in children receiving the antifibrinolytic drug epsilon aminocaproic acid. The effect was more pronounced in those children with cyanotic lesions and was confined to the intraoperative period.

It is not immediately obvious why tranexamic acid exerts its effect on blood loss. There is a large and sometimes contradictory literature concerning blood loss after cardiopulmonary bypass. Earlier work ${ }^{20}$ tended to stress the importance of excessive fibrinolysis, but as the technology of cardiopulmonary bypass has improved, more recent work in this area emphasizes the importance of an acquired platelet defect. ${ }^{2}$ We performed only simple clotbased estimates of coagulation (see Table II) and were unable to show any significant differences between the children with and without cyanosis, except for the widely described rise in hemoglobin concentration after chronic hypoxia. ${ }^{21}$ Suarez and associates, ${ }^{22}$ using biochemical markers of hemostasis in children with cyanotic congenital heart disease, showed highly significant increases in thromboxane, platelet factor IV, and $\beta$-thromboglobulin, indicating marked activation of the platelet system. They were unable to demonstrate any evidence of increased fibrinolytic activity. Tranexamic acid may improve hemostasis after surgery in two ways: It blocks plasmin-induced platelet activation, consequently preserving platelet function ${ }^{12}$; in addition, it is an effective inhibitor of fibinolysis. Whether one or either of these mechanisms is responsible for its effect in children is not possible to tell with our present study design.

More work is required to define the exact role of tranexamic acid in the control of bleeding after cardiac operations in children. In particular, a doseresponse study is necessary because it is possible that repeat postoperative doses or a continuous infusion of tranexamic acid may improve the drug's effect. In addition, detailed studies of coagulation will be necessary to define the exact mode of action of this drug in the postbypass coagulopathy of children.

\section{REFERENCES}

1. Woodman RC, Harker LA. Bleeding complications associated with cardiopulmonary bypass. Blood 1990;76:1680-97.

2. Harker LA. Bleeding after cardiopulmonary bypass. N Engl J Med 1986;314:1446-8.

3. Seear MD, Wadsworth LD, Rogers PC, Sheps SS, Ashmore PG. The effect of desmopressin acetate (DDAVP) on postoperative blood loss after cardiac operations in children. J Thorac Cardiovasc Surg 1989;98:217-9.

4. DeLeon SY, LoCicero J III, Ilbawi MM, Idriss FS. Repeat median sternotomy in pediatrics: experience in 164 consecutive cases. Ann Thorac Surg 1986;41:184-8.

5. Nicholls MD. Transfusion: morbidity and mortality. Anaesth Intens Care 1993;21:15-9.

6. Mammen EF, Koets MH, Washington BC, et al. Hemostasis changes during cardiopulmonary bypass surgery. Semin Thromb Hemost 1985;11:281-92.

7. Kucuk O, Kwaan HC, Frederickson J, Wade L, Green D. Increased fibrinolysis in patients undergoing cardiopulmonary bypass operation. Am J Hematol 1986;23:223-39.

8. Verstraete $M$. Clinical application of inhibitors of fibrinolysis. Drugs 1985;29:236-61.

9. Hardy JF, Desroches J. Natural and synthetic antifibrinolytics in cardiac surgery. Can J Anaesth 1992;39:353-65.

10. Ogston D. Current status of antifibrinolytic drugs. Blood Rev 1989:3:1-4.

11. Bekassy Z, Astedt B. Treatment with the fibrinolytic inhibitor tranexamic acid: Risk for thrombosis? Acta Obstet Gynecol Scand 1990;69:353-6.

12. Soslau G, Horrow J, Brodsky I. Effect of tranexamic acid on platelet ADP during extracorporeal circulation. Am J Hematol 1991;38:113-9.

13. Horrow JC, Van Riper DF, Strong MD, Brodsky I, Parmet $\mathrm{JL}$. Hemostatic effects of tranexamic acid and desmopressin during cardiac surgery. Circulation 1991;84:2063-70.

14. Vander Salm TJ, Ansell JE, Okike ON, et al. The role of epsilon aminocaproic acid in reducing bleeding after cardiac 
operation: a double-blind randomized study. J Thorac Cardiovasc Surg 1988;95:538-40.

15. Sterns LP, Lillehei $\mathbf{C W}$. Effect of epsilon aminocaproic acid upon blood loss following open heart surgery: an analysis of 340 patients. Can J Surg 1967;10:304-7.

16. Horrow JC, Hlavacek J, Strong MD, et al. Prophylactic tranexamic acid decreases bleeding after cardiac operations. J Thorac Cardiovasc Surg 1990;99:70-4.

17. Ovrum E, Am Holen E, Abdelnoor M, Oystese R, Ringdal $M$. Tranexamic acid (Cyclokapron) is not necessary to reduce blood loss after coronary artery bypass operations. J Thorac Cardiovasc Surg 1993;105:78-83.

18. McClure PD, Izsak J. The use of epsilon aminocaproic acid to reduce bleeding during cardiac bypass in children with congenital heart disease. Anesthesiology 1974;40:604-8.
19. Karski J, Teasdale S, Young P, Carroll J, Ivanov J, Glynn M. Antifibrinolysin therapy for the prevention of post CPB bleeding. Can J Anaesth 1991;38:A97.

20. Phillips C, Malon J, Deterling R Jr. Coagulation defects following extracorporeal circulation. Ann Surg 1963;157:31721.

21. Maurer H, McCue C, Robertson L, Haggins J. Correction of platelet dysfunction and bleeding in cyanotic congenital heart disease by simple red cell volume reduction. Am J Cardiol 1975;35:831-5.

22. Suarez CR, Menendez CE, Griffin AJ, Ow EP, Walenga JM, Fareed J. Cyanotic congenital heart disease in children: hemostatic disorders and relevance of molecular markers of hemostatis. Semin Thromb Hemost 1984;10 285-9.

\section{Bound volumes available to subscribers}

Bound volumes of The Journal of Thoracic and Cardiovascular Surgery are available to subscribers (only) for the 1996 issues from the Publisher, at a cost of $\$ 100.50$ for domestic, $\$ 128.94$ for Canadian, and $\$ 120.50$ for international subscribers for Vol. 111 (January-June) and Vol. 112 (July-December). Shipping charges are included. Each bound volume contains a subject and author index and all advertising is removed. Copies are shipped within 60 days after publication of the last issue of the volume. The binding is durable buckram with the Journal name, volume number, and year stamped in gold on the spine. Payment must accompany all orders. Contact Mosby-Year Book, Inc., Subscription Services, 11830 Westline Industrial Drive, St. Louis, Missouri 63146-3318, USA; phone $800-453-4351$ or 314-453-4351.

Subscriptions must be in force to qualify. Bound volumes are not available in place of a regular JourvaL subscription. 